\title{
Beliefs, Mental Health, Healthy Lifestyle Behaviors and Coping Strategies Used by College Students During the COVID-19 Pandemic
}

\author{
The Ohio State University \\ Alai Tan, PhD \\ The Ohio State University \\ Andreanna Pavan Hsieh, MPH \\ The Ohio State University \\ Megan Amaya, PhD, CHES \\ The Ohio State University \\ Erica Regan, MA, PhD \\ The Ohio State University \\ Leanne Stanley, MA, PhD \\ The Ohio State University
}

Bernadette Mazurek Melnyk PhD, APRN-CNP, FAANP, FNAP, FAAN

\begin{abstract}
Background: The COVID-19 pandemic has added substantial stress to the college student experience that could escalate the already existing student mental health crisis. Institutions of higher education have been called to explore ways in which they can promote and support the whole student.

Objective: To describe college students' beliefs about returning to campus, safety practices, mental health, and strategies used to cope with the COVID-19 pandemic.

Methods: A descriptive survey was emailed to a stratified random sample of undergraduate, graduate, and professional students $(N=14,459)$ from a large public Mid-west university. The survey measured beliefs about returning to campus and safety practices, mental health status (anxiety, depression, and burnout), and coping strategies used to deal with the stress of the pandemic.

Results: The response rate was 30.7\%. Thirty percent of students were not confident about returning to campus safely. Thirty-nine percent met the cut-off for clinical anxiety, 24\% for depression, and $39.9 \%$ for burnout. A substantial percentage used unhealthy lifestyle behaviors to cope with pandemic stress.
\end{abstract}

Conclusion: Institutions of higher education must accelerate mental health screening and services along with evidence-based preventive interventions and wellness programming for students.

Submitted 2 August 2021; accepted 30 September 2021

Keywords: young adult, wellness, mental health, healthy behaviors, higher education 
Prior to the COVID-19 pandemic, an analysis of the World Health Organization's (WHO) World Mental Health Survey determined that $20.3 \%$ of college students had a mental health condition (e.g., anxiety, substance use, mood disorder) and, among the $20.3 \%$ affected, $83.1 \%$ entered college with an already existing diagnosis (Auerbach et al., 2016). Being in a transitional stage of life, college students face numerous stressors that place them at risk for the development of a mental health disorder or exacerbation of an already existing one. COVID-19 has added to the amount of stress that students experience, and institutions of higher education (IHE) are being called to explore ways in which they can promote and support student mental health, including supporting the whole student (National Academies of Sciences, Engineering, and Medicine, 2021).

Wellness is an all-encompassing term used to describe a holistic approach to health. Reaching a state of wellness requires an individual to actively pursue a lifestyle that is beneficial to both their mental and physical well-being. However, the pursuit of wellness can be hindered by an individual's culture and environment. In the context of IHE COVID-19 restrictions and guidelines, student wellness has likely been impacted.

COVID-19 has caused considerable uncertainty in terms of financial security, personal and family health, and future planning. As of June 2020, the prevalence of anxiety disorders in adults was three times higher and the prevalence of depression was four times higher than values reported in the second quarter of 2019 (Czeisler et al., 2020). When compared to the general population, young adults (aged 18-24 years) more frequently reported anxiety and depressive disorders, COVID-19 related trauma and stressor-related disorders, increased substance use to deal with COVID-19 stress, and suicidal ideation. Specifically, 25\% of 18 to 24-year-olds in Czeisler et al. (2020) considered suicide since the start of the pandemic. Furthermore, a survey of 30,725 undergraduate students and 15,346 graduate/professional students from nine public universities also reported prevalence increases in depression (1.5x higher) and anxiety (2x higher) from 2019 (Chirikov et al., 2020). In terms of physical health, sedentary behaviors (e.g., watching TV, eating, and using electronic devices) has significantly increased and physical activity has significantly decreased in college aged students since the start of the pandemic (Gallè et al., 2020; Zheng et al., 2020). This is concerning as physical activity has a significant impact on alleviating depression (Kvam, Kleppe, Nordhus, \& Hovland, 2016) and anxiety (Stonerock, Hoffman, Smith, \& Blumenthal, 2015), both of which have skyrocketed during COVID-19.

In a multinational cross-sectional study with 21,369 college age students, stressors that impacted college student wellness generally fell into six categories: financial, personal health, love life, familial relationships, school relationships, and problems with loved ones (Karyotaki et al., 2020). Stress related to school relationships was significant in predicting depressive disorder, bipolar disorder, and generalized anxiety disorder, thus highlighting the important role that school environment plays in the well-being of students. School relationships play a larger role in the overall climate (i.e., culture) of the school as does the concept of school safety (Aldrige \& McChesney, 2018). From the student perspective, the COVID-19 pandemic has made campuses less safe because of how easily the disease transmits (Zhai \& Du, 2020).

Addressing the IHE student mental health crisis during and after COVID-19 will require a multicomponent intervention strategy as student mental health and overall wellness are impacted by various factors, some of which are controllable by individual-level action and others which are not. The current study was guided by the nine dimensions of wellness (Melnyk \& Neale, 2018) and the Socioecological Framework as described by the seminal McLeroy, Steckler, and Bibeau (1988) publication. The nine dimensions of wellness posits that wellness expands beyond the physical and mental to also include financial, intellectual, career, social, creative, environmental, and spiritual wellness. 
The Socioecological Framework emphasizes that an individual's health and ability to practice healthy behaviors are dependent on both the individual and their environment (social networks, institutions, community, and public policy). Using both frameworks could ultimately provide a comprehensive understanding of college students' overall wellness to guide university wellness services and programming related to COVID-19.

\section{Purpose and Relevance}

The purpose of this cross sectional study, performed by the Safe Campus \& Scientific Advisory Subgroup of the PostPandemic Operations Task Force at a large, multi-campus, Mid-west public university was to determine students' (1) readiness for returning to campus; (2) beliefs about safety practices; (3) mental health and well-being status; (4) healthy lifestyle behavior practices; (5) COVID-19 coping strategies; and (6) COVID-19 concerns and needs, including interest in University sponsored programming on health and wellness.

As stewards in assisting students with their education, health, and safety needs (Zhai \& Du, 2020), IHE must provide extensive wellness services in addition to guidelines for mitigating COVID-19 transmission. To create appropriate policies and guidelines to mitigate the negative impacts of the COVID-19 pandemic, IHE must establish the current status of student wellness and address the gaps with evidence-based programming and interventions.

\section{METHODS}

\section{Study Setting}

This study took place at large Mid-west public university that has six campuses located throughout the state. Over 68,000 students are enrolled at the University, with most students $(61,391)$ being enrolled at the central campus. The University's Chief Wellness Officer, co-chair of the Safe Campus and Scientific Advisory Sub-group, convened a group of experts from the University's One University Health and Wellness Council, the Office of Student Life, and the Office of Institutional Strategic Planning to develop the student survey.

\section{Recruitment}

An invitation to complete the survey was sent to a stratified random sample of students $(N=14,459)$ prior to the fall 2020 semester to assess their readiness for returning to campus, beliefs about safety practices (e.g., mask wearing and physical distancing), their mental health and wellness status, healthy lifestyle behavior practices, COVID-19 coping strategies, and specific COVID-19 concerns and needs, including interest in University sponsored programming on health and wellness. Exempt status for the confidential survey was obtained through the University's Institutional Review Board. 


\section{Measures: The Return to Campus Survey}

Demographic questions (e.g., age, gender, academic level, race, and campus location) and the following sections were included in the survey.

Beliefs about returning to campus and safety practices. Likert-type questions (not at all, a little, somewhat, moderately so, and very much so) were used to measure beliefs about returning to campus and safe practices to prevent COVID-19 spread. Belief questions included "I am confident we can return to campus safely," "I believe peers at my university will follow appropriate safety protocols when they return to campus," and "How willing are you to follow evidence-based guidelines on preventing the spread of COVID-19 when returning to campus?"

Burnout. The survey assessed burnout with a valid 1-item measure that asked "Overall, based on your definition of burnout, how would you rate your level of burnout?" A five-category ordinal scale is used to score the responses: 1 = no symptoms; 2 = occasional stress, but don't feel burned out; 3 = definitely burning out and am experiencing physical or emotion exhaustion; 4 = symptoms of burnout won't go away; and $5=$ I feel completely burned out and often wonder if I can go on (Dolan et al., 2015). A positive score for burnout is $\geq 3$.

Anxiety. The valid and reliable GAD-2 scale measured self-reported clinical anxiety (Kroenke, Spitzer, Williams, Monahan, \& Löwe, 2007). The 2-item questionnaire asks participants about experiencing symptoms of anxiety (feeling nervous, anxious, or on edge; and not being able to stop or control worrying) over the past two weeks. Participants respond to the questions using a four-point Likert-type scale with scores ranging from 0 (not at all) to 3 (nearly every day). Response scores are totaled and a score $\geq 3$ indicates a clinically significant finding for anxiety. In prior studies, Cronbach's alpha were reported as 0.76 to 0.81 (Melnyk et al., 2021; Staples et al., 2019). In this study sample, the Cronbach's alpha was 0.81 .

Depression. The valid and reliable PHQ-2 measures self-reported depression (Kroenke, Spitzer, \& Williams, 2003). It contains questions about experiencing symptoms of depression (little interest or pleasure in doing things and feeling down, depressed, or hopeless) over the past two weeks. Participants respond to the questions using a fourpoint Likert-type scale with scores ranging from 0 (not at all) to 3 (nearly every day). Response scores are totaled and a score $\geq 3$ indicates a clinically significant finding of depression. In prior studies, Cronbach's alpha were reported as 0.76 to 0.83 (Melnyk et al., 2021; Staples et al., 2019). In this study sample, the Cronbach's alpha was 0.73.

Healthy lifestyle behaviors. Additional Likert-type questions were used to assess healthy lifestyle behaviors in terms of changes in amount daily physical activity (the same, less than usual, more than usual); eating patterns (the same, less healthy, more healthy); and amount of sleep (the same, less than usual, more than usual). Also included was a select all that apply question to determine what students were using to cope with COVID-19: engaged in wellness programs offered by the University; increased the use of tobacco/vaping products; increased use of alcohol; had sessions with a mental health counselor; had sessions with a health and wellness coach; connected with friends/family; volunteered; did kind things for others; learned a new skill; engaged in a personal spiritual practice; increased my physical activity; ate more or increased my consumption of unhealthy types of food; increased sleep; practiced mindfulness; used gratitude; other; and none of the above.

Virtual programming and services: Accessibility, interest, and utilization. Likert-type questions (strongly disagree, disagree, neither disagree or agree, agree, strongly agree) were used to assess students' intent to use university 
programming on health and wellness topics; ability to access virtual programming; satisfaction with the amount of virtual programming offered; use of virtual programming prior to COVID-19; and future use of virtual programming.

\section{Statistical Analysis}

Descriptive statistics summarized students' demographics, beliefs about returning to campus (including safety practices and concerns), perceptions of virtual programming and services, mental health (anxiety, depression, and burnout), changes in healthy lifestyle behaviors during the pandemic, and coping strategies used to deal with COVID19. Chi-Square tests compared key variables (beliefs about returning to campus safely, positive screenings for anxiety, and positive screenings for depression) by type of student (professional, graduate, central campus undergraduate, and regional campus undergraduate students), and race/ethnicity (non-Hispanic White, Black/African American, Asian/Pacific Islander, and Other). Participants who selected Native American/American Indian/Alaskan Native or Middle Eastern/Arab American were grouped together for analysis under the heading "Other" as these categories were too small to yield reliable results alone. SAS version 9.4 was used for all analyses.

\section{RESULTS}

The survey obtained responses from 4,441 students, a 30.7\% response rate. Most students were 22.4 years-of-age (SD $=5.0)$, female $(61 \%)$, non-Hispanic White $(71 \%)$, and at the undergraduate level $(76.6 \%)$. A full listing of student characteristics can be found in Table 1 . 
Table 1. Student Characteristics ( $\mathrm{n}=4,441)$

\begin{tabular}{|c|c|c|}
\hline Characteristics & $\mathbf{N}$ & $\%$ \\
\hline \multicolumn{3}{|l|}{ Age (Mean \pm SD: $22.4 \pm 5.0)$} \\
\hline$<20$ & 1135 & 25.6 \\
\hline $21-24$ & 2355 & 53.0 \\
\hline $25-29$ & 554 & 12.5 \\
\hline $30-39$ & 224 & 5.0 \\
\hline $40+$ & 85 & 2.0 \\
\hline Missing & 88 & 2.0 \\
\hline \multicolumn{3}{|l|}{ Gender } \\
\hline Man & 1620 & 36.5 \\
\hline Woman & 2711 & 61.0 \\
\hline Other & 52 & 1.2 \\
\hline Missing & 58 & 1.3 \\
\hline \multicolumn{3}{|l|}{ Race/Ethnicity } \\
\hline Non-Hispanic White & 3153 & 71.0 \\
\hline African American & 269 & 6.1 \\
\hline Asian/Pacific Islander (including Hawaiian) & 561 & 12.6 \\
\hline Hispanic / Latino & 215 & 4.8 \\
\hline $\begin{array}{l}\text { Other (including Native American/American Indian/Alaskan Native and Middle Eastern/Arab } \\
\text { American) }\end{array}$ & 94 & 2.1 \\
\hline Missing & 149 & 3.4 \\
\hline \multicolumn{3}{|l|}{ Academic level } \\
\hline Professional ${ }^{\S}$ & 382 & 8.6 \\
\hline Graduate $^{\S}$ & 657 & 14.8 \\
\hline Undergraduate, Central Campus & 2522 & 56.8 \\
\hline Undergraduate, Regional Campus & 880 & 19.8 \\
\hline \multicolumn{3}{|l|}{ Year(s) in school (undergraduate students only, $n=3412$ ) } \\
\hline 1 & 27 & 0.8 \\
\hline 2 & 1231 & 36.1 \\
\hline 3 & 959 & 28.1 \\
\hline 4 & 892 & 26.1 \\
\hline 5 & 275 & 8.1 \\
\hline missing & 28 & 0.8 \\
\hline
\end{tabular}

Note. ${ }^{\mathbb{S} A l l}$ professional and graduate students were located at the central campus location.

\section{Return to Campus Beliefs of Students}

Almost 30\% of all students were not at all confident about being able to return to campus safely, however, $49 \%$ were at least somewhat confident when combining the responses of "somewhat" with "moderately so" and "very much so" (Table 2). 
Table 2. Beliefs on Returning to Campus

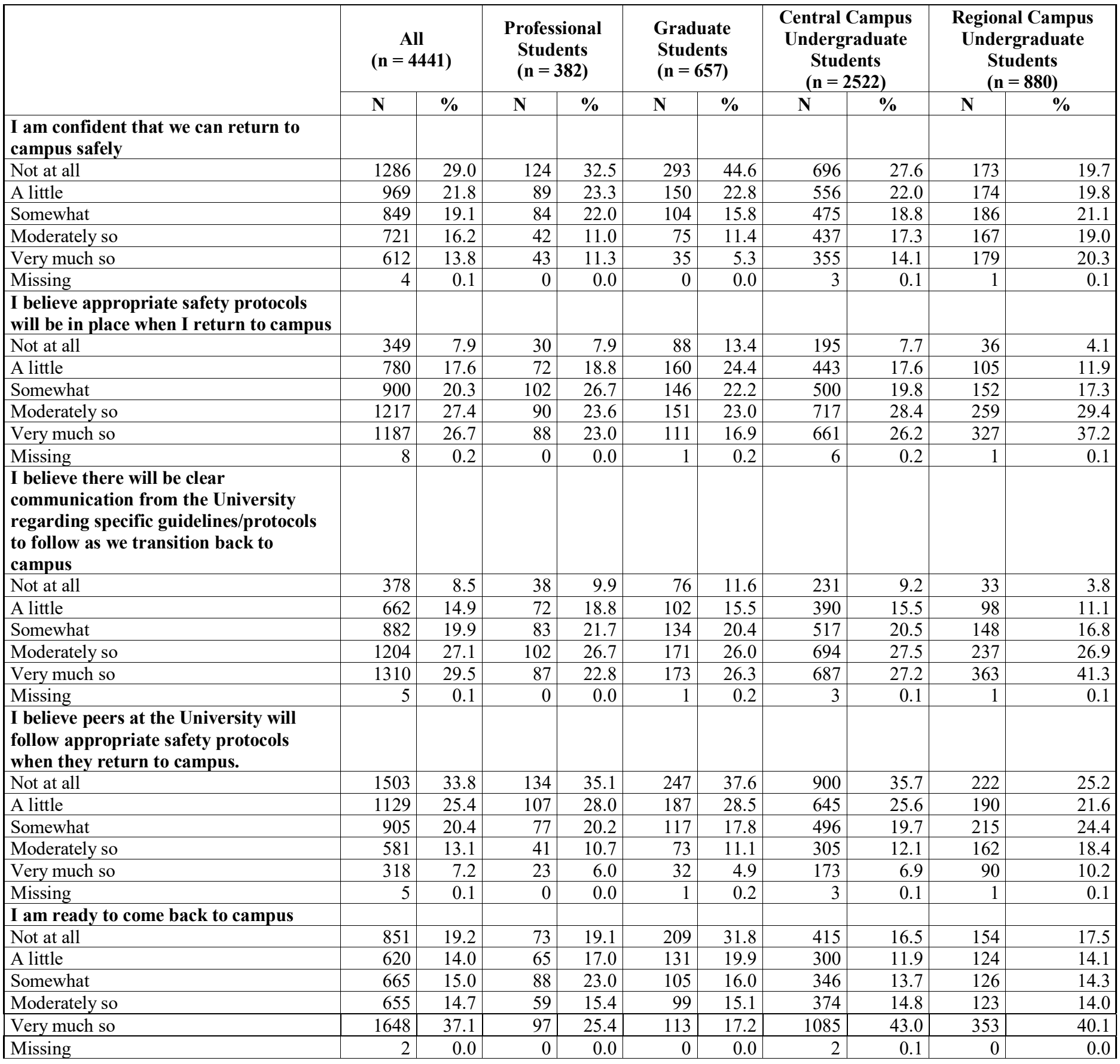

Graduate students were significantly less confident about returning to campus safely $(p<0.001$; Figure 1$)$ when compared to other academic levels. In terms of race/ethnicity, ethnic and racial diversity populations (African American/Black [36\%], Asian/Pacific Islander [40\%], Hispanic [34\%], and Other $[47 \%])$ had significantly higher $(p$ $<0.001)$ rates of reporting "not at all confident" about returning to campus than non-Hispanic White students (25\%), with those grouped in the other category having the least amount of confidence. 
Figure 1. Level of Student Confidence in Being Able to Return to Campus Safely by Type of Student

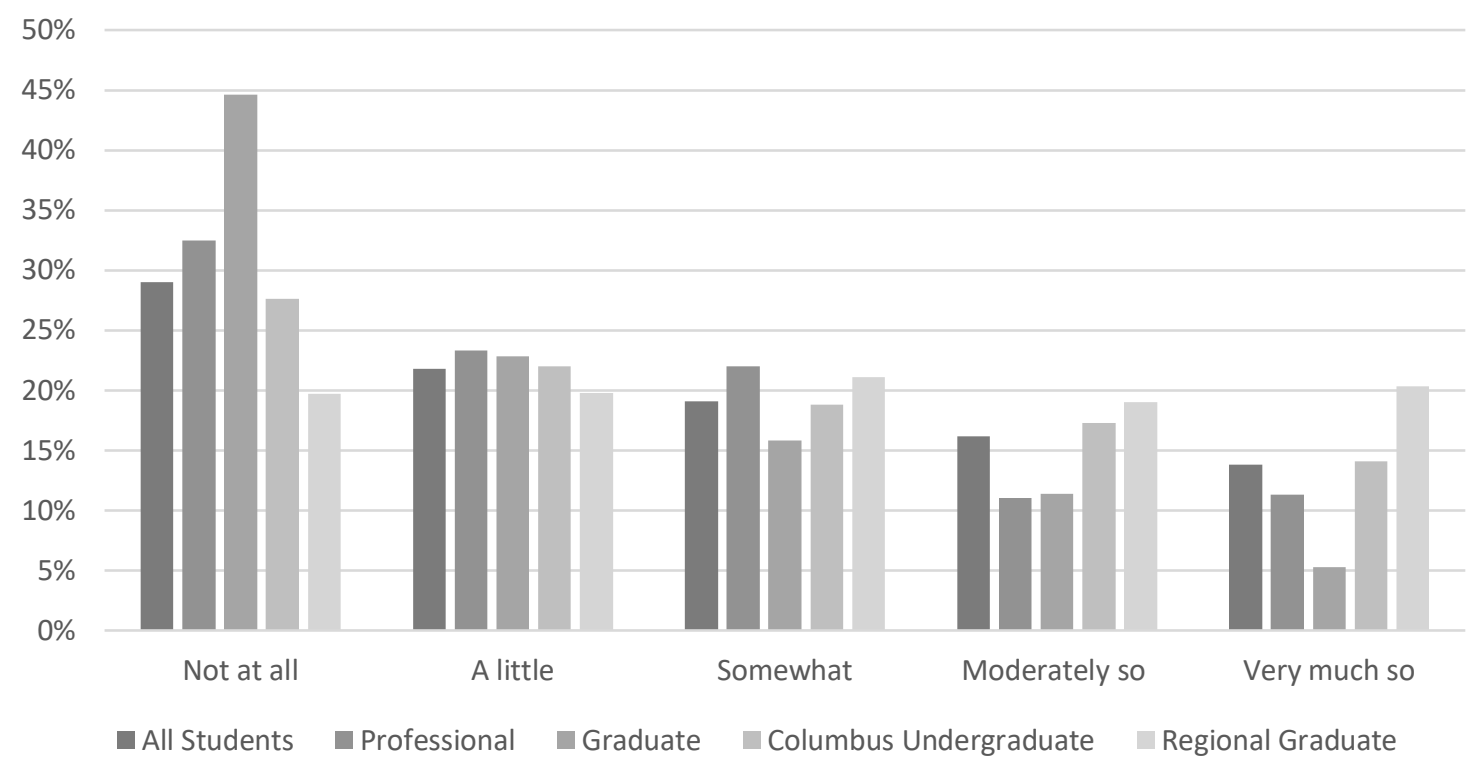

Figure 1. Level of confidence for returning to campus was assessed by asking "How confident are you about returning to campus safely?" Group differences were assessed via a Chi Square test. Graduate students had significantly more stress over finance than the other academic levels $(p<0.001)$.

In terms of student beliefs about proper safety protocols being in place when they return to campus, approximately three quarters $(74 \%)$ at least somewhat believed such protocols would be present, with regional campus undergraduates holding the highest beliefs. In a similar manner, regional campus undergraduates expressed more confidence about receiving clear communication from the University than the other types of students. Only 37.1\% of students reported "very much so" being ready to return to campus (Table 2).

A large proportion of students reported having some level of concern about contracting COVID-19 once returning to campus, with as few as $12.3 \%$ voicing no concern at all. Only $40 \%$ of students reported "somewhat" believing that their University peers would follow the appropriate safety protocols. Regional campus undergraduate students had higher beliefs regarding their peers following appropriate safety protocols. Overall, students expressed the most concern about contracting COVID-19 (58.3\%), passing COVID-19 on to their family/loved ones (64.9\%), and their own level of anxiety or stress (48.1\%; Table 3). 
Table 3. Concerns about Returning to Campus

\begin{tabular}{|c|c|c|c|c|c|c|c|c|c|c|}
\hline & \multicolumn{2}{|c|}{$\begin{array}{c}\text { All } \\
(\mathrm{n}=\mathbf{4 4 4 1})\end{array}$} & \multicolumn{2}{|c|}{$\begin{array}{l}\text { Professional } \\
\text { Students } \\
(\mathbf{n}=\mathbf{3 8 2})\end{array}$} & \multicolumn{2}{|c|}{$\begin{array}{l}\text { Graduate } \\
\text { Students } \\
(\mathrm{n}=657)\end{array}$} & \multicolumn{2}{|c|}{$\begin{array}{l}\text { Central Campus } \\
\text { Undergraduate } \\
\text { Students } \\
(\mathbf{n}=\mathbf{2 5 2 2})\end{array}$} & \multicolumn{2}{|c|}{$\begin{array}{c}\text { Regional } \\
\text { Campus } \\
\text { Undergraduate } \\
\text { Students } \\
(\mathbf{n}=\mathbf{8 8 0})\end{array}$} \\
\hline & $\mathbf{N}$ & $\%$ & $\mathbf{N}$ & $\%$ & $\mathbf{N}$ & $\%$ & $\mathbf{N}$ & $\%$ & $\mathbf{N}$ & $\%$ \\
\hline \multicolumn{11}{|l|}{$\begin{array}{l}\text { How concerned are you about getting } \\
\text { COVID-19 once we return to campus? }\end{array}$} \\
\hline Not at all & 547 & 12.3 & 31 & 8.1 & 27 & 4.1 & 307 & 12.2 & 182 & 20.7 \\
\hline A little & 672 & 15.1 & 55 & 14.4 & 76 & 11.6 & 413 & 16.4 & 128 & 14.5 \\
\hline Somewhat & 897 & 20.2 & 79 & 20.7 & 124 & 18.9 & 500 & 19.8 & 194 & 22.0 \\
\hline Moderately so & 967 & 21.8 & 108 & 28.3 & 137 & 20.9 & 542 & 21.5 & 180 & 20.5 \\
\hline Very much so & 1355 & 30.5 & 109 & 28.5 & 293 & 44.6 & 757 & 30.0 & 196 & 22.3 \\
\hline Missing & 3 & 0.1 & 0 & 0.0 & 0 & 0.0 & 3 & 0.1 & 0 & 0.0 \\
\hline \multicolumn{11}{|l|}{$\begin{array}{l}\text { What are your greatest concerns about } \\
\text { returning to campus? (Please check all } \\
\text { that apply) }\end{array}$} \\
\hline Contracting COVID-19 & 2588 & 58.3 & 235 & 61.5 & 458 & 69.7 & 1455 & 57.7 & 440 & 50.0 \\
\hline $\begin{array}{l}\text { Passing COVID-19 on to my } \\
\text { family/loved ones }\end{array}$ & 2880 & 64.9 & 261 & 68.3 & 430 & 65.4 & 1629 & 64.6 & 560 & 63.6 \\
\hline Childcare for my children & 100 & 2.3 & 10 & 2.6 & 34 & 5.2 & 22 & 0.9 & 34 & 3.9 \\
\hline Use of public transportation & 1003 & 22.6 & 62 & 16.2 & 215 & 32.7 & 655 & 26.0 & 71 & 8.1 \\
\hline $\begin{array}{l}\text { Colleagues who may not follow protocols } \\
\text { that will keep me safe }\end{array}$ & 2913 & 65.6 & 270 & 70.7 & 504 & 76.7 & 1641 & 65.1 & 498 & 56.6 \\
\hline $\begin{array}{l}\text { Other members of the University } \\
\text { community who may not follow } \\
\text { protocols that will keep me safe }\end{array}$ & 2310 & 52.0 & 209 & 54.7 & 450 & 68.5 & 1312 & 52.0 & 339 & 38.5 \\
\hline $\begin{array}{l}\text { How I will take care of a family member } \\
\text { after I return to campus }\end{array}$ & 275 & 6.2 & 16 & 4.2 & 56 & 8.5 & 144 & 5.7 & 59 & 6.7 \\
\hline My anxiety/level of stress & 2136 & 48.1 & 177 & 46.3 & 329 & 50.1 & 1220 & 48.4 & 410 & 46.6 \\
\hline $\begin{array}{l}\text { I am not comfortable coming back to } \\
\text { campus and would prefer to work from } \\
\text { home }\end{array}$ & 1205 & 27.1 & 91 & 23.8 & 268 & 40.8 & 615 & 24.4 & 231 & 26.3 \\
\hline Other & 517 & 11.6 & 49 & 12.8 & 51 & 7.8 & 301 & 11.9 & 116 & 13.2 \\
\hline
\end{tabular}

Although less than $50 \%$ of students believed that they knew how to best prevent the spread of COVID-19, students reported strong beliefs in the importance of physical distancing and mask wearing with more than 60\% indicating that they believed in these preventative measures "a lot." Although only $34.7 \%$ of students believed that daily health screenings were a critical preventive measure, $77.2 \%$ of students were very willing to follow evidencebased guidelines for prevention when returning to campus (Table 4). 
Table 4. Beliefs on COVID-19 Prevention Procedures

\begin{tabular}{|c|c|c|c|c|c|c|c|c|c|c|}
\hline & \multicolumn{2}{|c|}{$\begin{array}{c}\text { All } \\
(n=4441)\end{array}$} & \multicolumn{2}{|c|}{$\begin{array}{l}\text { Professional } \\
\text { Students } \\
(\mathbf{n}=\mathbf{3 8 2})\end{array}$} & \multicolumn{2}{|c|}{$\begin{array}{c}\text { Graduate } \\
\text { Students } \\
(n=657)\end{array}$} & \multicolumn{2}{|c|}{$\begin{array}{l}\text { Central Campus } \\
\text { Undergraduate } \\
\text { Students } \\
(\mathbf{n}=\mathbf{2 5 2 2})\end{array}$} & \multicolumn{2}{|c|}{$\begin{array}{c}\text { Regional } \\
\text { Campus } \\
\text { Undergraduate } \\
\text { Students } \\
(\mathbf{n}=\mathbf{8 8 0}) \\
\end{array}$} \\
\hline & $\mathbf{N}$ & $\%$ & $\mathbf{N}$ & $\%$ & $\mathbf{N}$ & $\%$ & $\mathbf{N}$ & $\%$ & $\mathbf{N}$ & $\%$ \\
\hline \multicolumn{11}{|c|}{$\begin{array}{l}\text { I know how best to prevent the spread } \\
\text { of COVID-19 once we return to } \\
\text { campus. }\end{array}$} \\
\hline Not at all & 107 & 2.4 & 10 & 2.6 & 26 & 4.0 & 53 & 2.1 & 18 & 2.0 \\
\hline A little & 231 & 5.2 & 27 & 7.1 & 53 & 8.1 & 112 & 4.4 & 39 & 4.4 \\
\hline Somewhat & 575 & 12.9 & 54 & 14.1 & 105 & 16.0 & 315 & 12.5 & 101 & 11.5 \\
\hline Moderately so & 1637 & 36.9 & 144 & 37.7 & 243 & 37.0 & 957 & 37.9 & 293 & 33.3 \\
\hline Very much so & 1887 & 42.5 & 147 & 38.5 & 229 & 34.9 & 1083 & 42.9 & 428 & 48.6 \\
\hline Missing & 4 & 0.1 & 0 & 0.0 & 1 & 0.2 & 2 & 0.1 & 1 & 0.1 \\
\hline \multicolumn{11}{|c|}{$\begin{array}{l}\text { How much do you believe physical } \\
\text { distancing is critical in preventing the } \\
\text { spread of COVID-19? }\end{array}$} \\
\hline Not at all & 115 & 2.6 & & & 5 & 0.8 & 52 & 2.1 & 58 & 6.6 \\
\hline A little & 228 & 5.1 & 11 & 2.9 & 20 & 3.0 & 123 & 4.9 & 74 & 8.4 \\
\hline Somewhat & 477 & 10.7 & 33 & 8.6 & 37 & 5.6 & 257 & 10.2 & 150 & 17.0 \\
\hline Moderately & 900 & 20.3 & 69 & 18.1 & 78 & 11.9 & 531 & 21.1 & 222 & 25.2 \\
\hline A lot & 2715 & 61.1 & 268 & 70.2 & 517 & 78.7 & 1556 & 61.7 & 374 & 42.5 \\
\hline Missing & 6 & 0.1 & 1 & 0.3 & 0 & 0.0 & 3 & 0.1 & 2 & 0.2 \\
\hline \multicolumn{11}{|c|}{$\begin{array}{l}\text { How much do you believe wearing a } \\
\text { mask is critical in preventing the } \\
\text { spread of COVID-19? }\end{array}$} \\
\hline Not at all & 175 & 3.9 & 4 & 1.0 & 6 & 0.9 & 71 & 2.8 & 94 & 10.7 \\
\hline A little & 187 & 4.2 & 8 & 2.1 & 8 & 1.2 & 90 & 3.6 & 81 & 9.2 \\
\hline Somewhat & 344 & 7.7 & 19 & 5.0 & 22 & 3.3 & 171 & 6.8 & 132 & 15.0 \\
\hline Moderately & 711 & 16.0 & 63 & 16.5 & 69 & 10.5 & 407 & 16.1 & 172 & 19.5 \\
\hline A lot & 3018 & 68.0 & 286 & 74.9 & 551 & 83.9 & 1781 & 70.6 & 400 & 45.5 \\
\hline Missing & 6 & 0.1 & 2 & 0.5 & 1 & 0.2 & 2 & 0.1 & 1 & 0.1 \\
\hline \multicolumn{11}{|c|}{$\begin{array}{l}\text { How much do you believe daily health } \\
\text { screenings (for example, temperature } \\
\text { checks) are critical in preventing the } \\
\text { spread of COVID-19? }\end{array}$} \\
\hline Not at all & 282 & 6.3 & 15 & 3.9 & 27 & 4.1 & 157 & 6.2 & 83 & 9.4 \\
\hline A little & 494 & 11.1 & 39 & 10.2 & 57 & 8.7 & 270 & 10.7 & 128 & 14.5 \\
\hline Some what & 864 & 19.5 & 92 & 24.1 & 118 & 18.0 & 475 & 18.8 & 179 & 20.3 \\
\hline Moderately so & 1255 & 28.3 & 110 & 28.8 & 172 & 26.2 & 749 & 29.7 & 224 & 25.5 \\
\hline Very much so & 1540 & 34.7 & 125 & 32.7 & 283 & 43.1 & 868 & 34.4 & 264 & 30.0 \\
\hline Missing & 6 & 0.1 & 1 & 0.3 & 0 & 0.0 & 3 & 0.1 & 2 & 0.2 \\
\hline \multicolumn{11}{|c|}{$\begin{array}{l}\text { How willing are you to follow evidence- } \\
\text { based guidelines/recommendations on } \\
\text { preventing the spread of COVID-19 } \\
\text { when coming back to campus (for } \\
\text { example, ffeet distancing, wearing a } \\
\text { mask)? }\end{array}$} \\
\hline Not at all & 48 & 1.1 & 3 & 0.8 & 3 & 0.5 & 21 & 0.8 & 21 & 2.4 \\
\hline A little & 90 & 2.0 & 4 & 1.0 & 2 & 0.3 & 50 & 2.0 & 34 & 3.9 \\
\hline Some what & 208 & 4.7 & 10 & 2.6 & 10 & 1.5 & 106 & 4.2 & 82 & 9.3 \\
\hline Moderately so & 662 & 14.9 & 36 & 9.4 & 43 & 6.5 & 394 & 15.6 & 189 & 21.5 \\
\hline Very much so & 3430 & 77.2 & 329 & 86.1 & 599 & 91.2 & 1948 & 77.2 & 554 & 63.0 \\
\hline Missing & 3 & 0.1 & 0 & 0.0 & 0 & 0.0 & 3 & 0.1 & 0 & 0.0 \\
\hline
\end{tabular}


Of the programming available, students expressed the most interest in wellness, fitness, or recreational activity; student organization meetings; and student events (e.g., guest speaker, awards ceremony; Figure 2). Approximately a quarter also expressed interest in meditation/mindfulness activities, mental health workshops or programs on stress reduction and coping, and accessing a mental health counseling appointment.

Figure 2. Type of Virtual Health and Wellness Offerings that Students Intend to Participate in After Returning to Campus

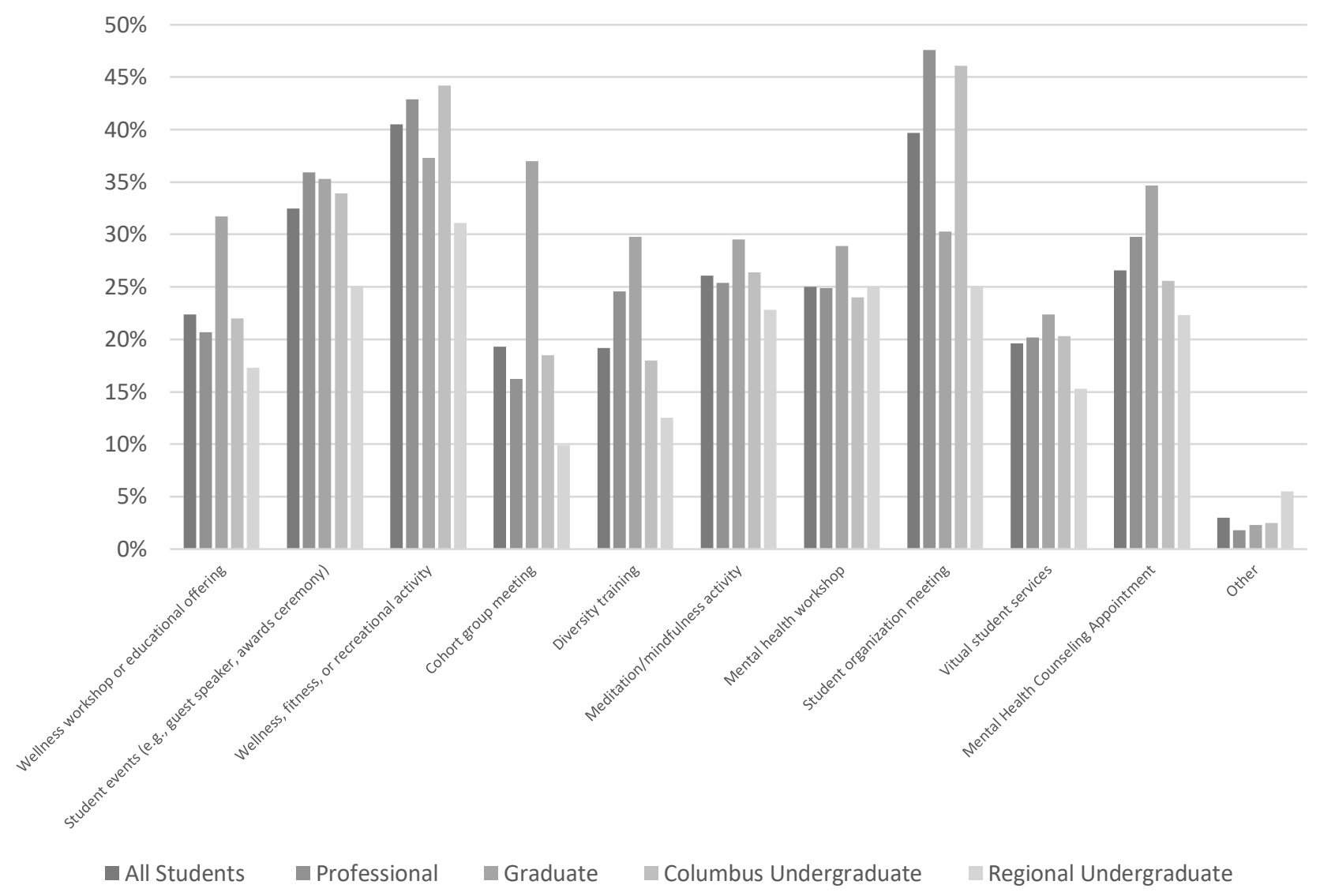

Figure 2. The university offers a variety of online programming to promote social connection, student engagement with the university, and mental wellness. Students were asked to select all programs that they intended to participate in, thus, the percentages total $>100$.

\section{Mental Health and Coping Strategies}

Thirty-nine percent of the students screened positive for generalized anxiety disorder and $24.1 \%$ screened positive for depression. Figure 3 shows the prevalence of positive anxiety and depression screenings by academic level. There was no significant difference between academic level and a positive GAD-2 screening $(\phi=0.128)$. In terms of depression, regional campus undergraduates had significantly higher rates of depression (27\% with PHQ- $2 \geq 3$; $\mathrm{p}=$ 0.023) than professional students, graduate students, and central campus undergraduates. 
Figure 3. Anxiety and Depression in Students by Academic Program

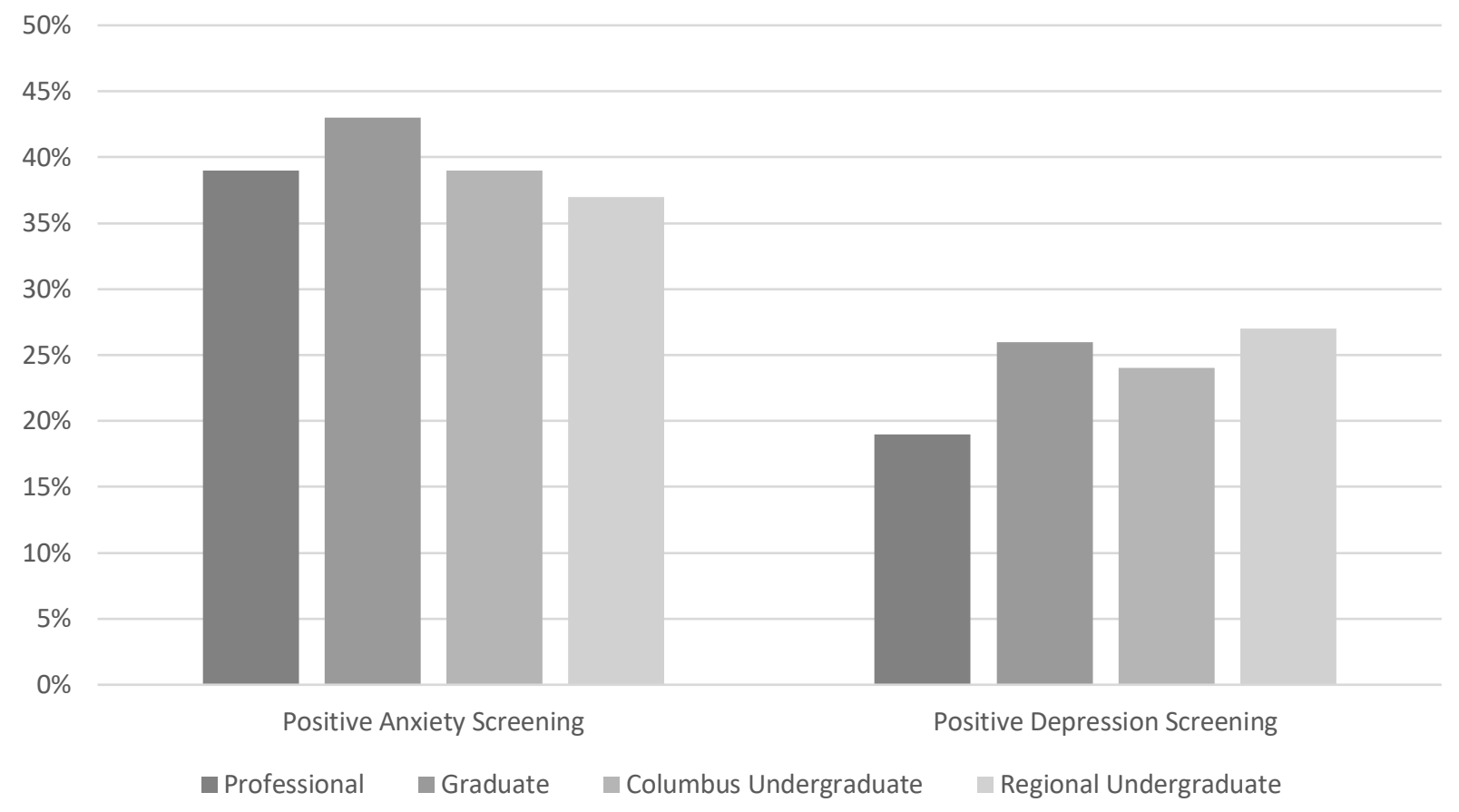

Figure 3. Clinically significant levels of depression and anxiety were assessed in this student population through use of the Patient Health Questionnaire 2-Item Scale and the Generalized Anxiety Disorder 2-Item scale. Students who scored $\geq 3$ on the scales were considered to have a "positive" screening. Group differences were assessed via a Chi Square test. There was no significant difference between academic level and a positive GAD-2 screening $(p=0.128)$ or positive PHQ-2 screening ( $\mathrm{p}=0.023)$.

When anxiety and depression were analyzed by student race/ethnicity, Hispanic students reported significantly more anxiety $(48 \% ; \mathrm{p}=0.012)$ than the Non-Hispanic White $(39 \%)$, Black/African American (40\%), Asian/Pacific Islander (35\%), and Other students (46\%). All minority students (Black/African American [32\%]; Asian/Pacific Islander [27\%]; Hispanic [32\%]; and Other [32\%]) reported significantly more depression $(\mathrm{p}<0.001)$ than the NonHispanic White students $(22 \%)$.

Results from the 1-item burnout question indicated that $39.9 \%$ of students were experiencing burnout $(29 \%$ of students had at least $1+$ symptom of burnout; $8.2 \%$ had symptoms that would not go away; and $2.5 \%$ felt completely burnout out and often wondered if they could go on).

Sixteen percent of students indicated having no stress about returning to campus. As few as 14\% indicated no stress over finances and regional campus undergraduates had significantly higher levels of financial stress when compared to the other academic levels $(p=0.002$; Figure 4$)$. 
Figure 4. Stress Over Finances by Academic Level

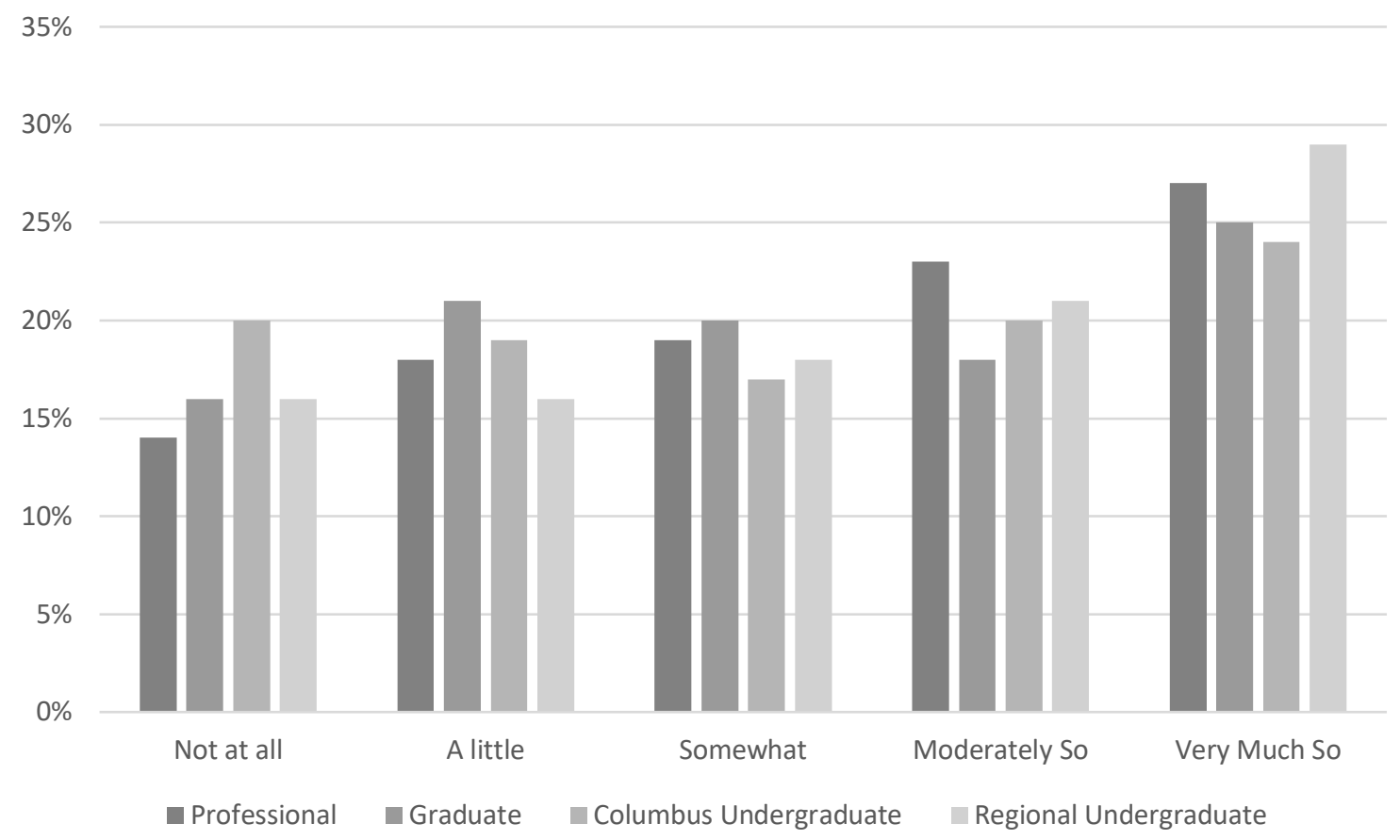

Figure 4. Stress over finances were assessed in this student population by asking "How much stress are you currently feeling over finances?” Group differences were assessed via a Chi Square test. Regional undergraduate students had significantly more stress over finance than the other academic levels $(p=0.002)$.

Over $50 \%$ of students denoted that they have problems coping with the stress in their life and $29.2 \%$ were experiencing at least one symptom of burnout (e.g., physical or emotional exhaustion). In relation to this inability to cope, $33.8 \%$ of students expressed being at least somewhat interested in participating in stress management programming (Table 5). 
Table 5. Student's Stress and Burnout

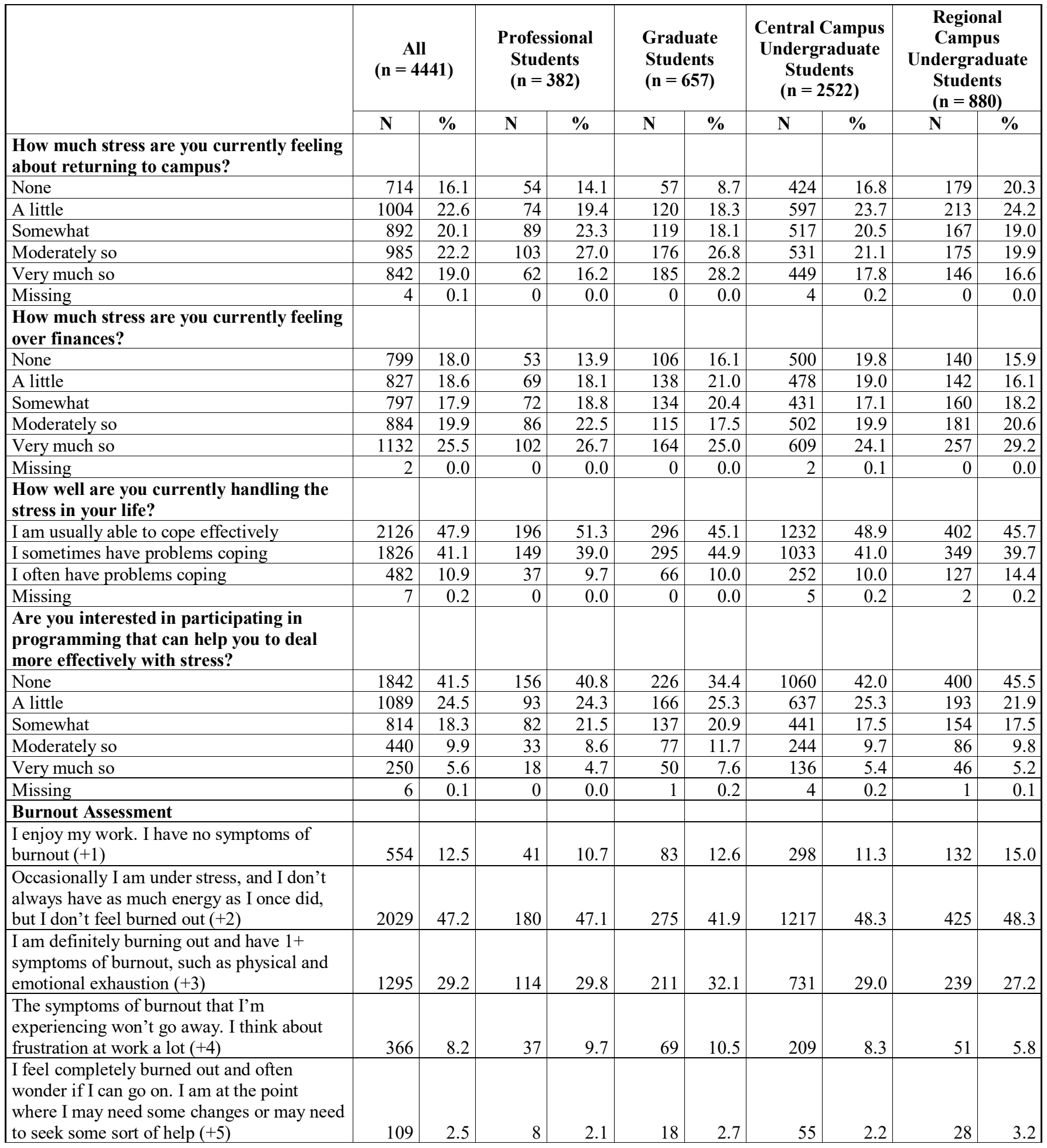


Figure 5 shows the strategies used by at least $10 \%$ of students to cope with COVID-19. Connecting with family and friends was the most commonly reported coping strategy (70.1\%), followed by learning a new skill (42\%) and increased physical activity (35.1\%). Only $2 \%$ of the students engaged in wellness programs offered to cope with COVID-19. Thirty-four percent of the students indicated that they used increased sleep to cope with COVID-19. Increased use of alcohol to cope with the pandemic was reported by $15.5 \%$ of the students and increased use of tobacco and vaping was reported by $5.9 \%$ of the students.

Figure 5. Strategies Used by 10\% or More Students to Cope with COVID-19

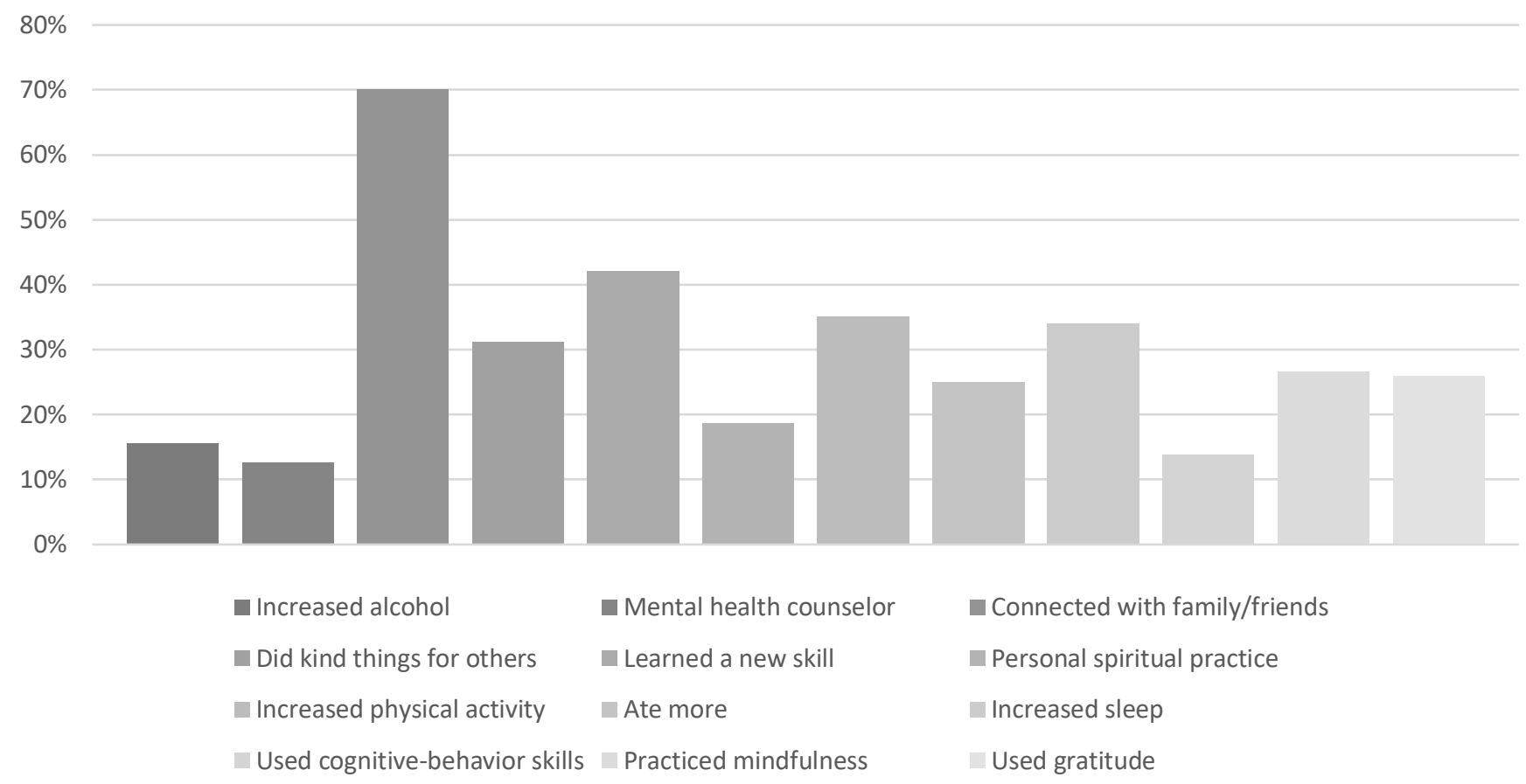

Figure 5. On the Return to Campus survey, students were asked to select which strategies they were using to cope with the stress of COVID-19. Students were asked to select all options that applied, therefore the percentage totals more than $100 \%$.

\section{Healthy Lifestyle Behaviors}

To assess COVID-19's impact on healthy lifestyle behaviors, students were asked how their daily physical activity, eating habits, amount of sleep, and coping mechanisms had changed since the start of the pandemic. Fifty-two percent of students indicated that they had participated in less physical activity than usual. Exercising more than usual was the least frequently selected option. Forty-three percent reported that their eating patterns had stayed the same. Thirtyfive percent reported that they had been eating less healthy. Like healthy eating, $44.2 \%$ of the students reported that there had been no change in their sleep. However, 26.5\% expressed that they had been sleeping less and 29.2\% reported that they had been sleeping more. The top three motivators for exercising and eating a nutritious diet were "it helps me feel good about myself," "I want to be in control of my weight," and "I want to be strong." A third of 
students $(32.9 \%)$ expressed being at least somewhat interested in wellness programming after returning to campus (Table 6).

Table 6. Students' Healthy Lifestyle Behaviors

\begin{tabular}{|c|c|c|c|c|c|c|c|c|c|c|}
\hline & \multicolumn{2}{|c|}{$\begin{array}{c}\text { All } \\
(n=4441)\end{array}$} & \multicolumn{2}{|c|}{$\begin{array}{l}\text { Professional } \\
\text { Students } \\
(\mathbf{n}=\mathbf{3 8 2})\end{array}$} & \multicolumn{2}{|c|}{$\begin{array}{l}\text { Graduate } \\
\text { Students } \\
(\mathrm{n}=657)\end{array}$} & \multicolumn{2}{|c|}{$\begin{array}{l}\text { Central Campus } \\
\text { Undergraduate } \\
\text { Students } \\
(\mathbf{n}=\mathbf{2 5 2 2})\end{array}$} & \multicolumn{2}{|c|}{$\begin{array}{c}\text { Regional } \\
\text { Campus } \\
\text { Undergraduate } \\
\text { Students } \\
(\mathbf{n}=\mathbf{8 8 0}) \\
\end{array}$} \\
\hline & $\mathbf{N}$ & $\%$ & $\mathbf{N}$ & $\%$ & $\mathbf{N}$ & $\%$ & $\mathbf{N}$ & $\%$ & $\mathbf{N}$ & $\%$ \\
\hline \multicolumn{11}{|l|}{$\begin{array}{l}\text { What has been your level of daily } \\
\text { physical activity since COVID-19? }\end{array}$} \\
\hline The same & 1107 & 24.9 & 96 & 25.1 & 124 & 18.9 & 605 & 24.0 & 282 & 32.0 \\
\hline Less than usual & 2332 & 52.5 & 186 & 48.7 & 392 & 59.7 & 1348 & 53.4 & 406 & 46.1 \\
\hline More than usual & 993 & 22.4 & 98 & 25.7 & 138 & 21.0 & 565 & 22.4 & 192 & 21.8 \\
\hline Missing & 9 & 0.2 & 2 & 0.5 & 3 & 0.5 & 4 & 0.2 & 0 & 0.0 \\
\hline \multicolumn{11}{|l|}{$\begin{array}{l}\text { How have your eating patterns } \\
\text { changed since COVID-19? }\end{array}$} \\
\hline The same & 1915 & 43.1 & 171 & 44.8 & 279 & 42.5 & 1071 & 42.5 & 394 & 44.8 \\
\hline Less healthy & 1559 & 35.1 & 131 & 34.3 & 209 & 31.8 & 889 & 35.2 & 330 & 37.5 \\
\hline More healthy & 959 & 21.6 & 78 & 20.4 & 169 & 25.7 & 557 & 22.1 & 155 & 17.6 \\
\hline Missing & 8 & 0.2 & 2 & 0.5 & 0 & 0.0 & 5 & 0.2 & 1 & 0.1 \\
\hline \multicolumn{11}{|l|}{$\begin{array}{l}\text { How has your sleep been impacted by } \\
\text { COVID-19? }\end{array}$} \\
\hline No change & 1958 & 44.1 & 177 & 46.3 & 280 & 42.6 & 1124 & 44.6 & 377 & 42.8 \\
\hline Less than usual & 1178 & 26.5 & 97 & 25.4 & 194 & 29.5 & 623 & 24.7 & 264 & 30.0 \\
\hline More than usual & 1298 & 29.2 & 106 & 27.7 & 183 & 27.9 & 772 & 30.6 & 237 & 26.9 \\
\hline Missing & 7 & 0.2 & 2 & 0.5 & 0 & 0.0 & 3 & 0.1 & 2 & 0.2 \\
\hline \multicolumn{11}{|l|}{$\begin{array}{l}\text { If you exercise regularly and/or } \\
\text { maintain a nutritious diet, which of the } \\
\text { following motivates you to do so? } \\
\text { (Please select all that apply) }\end{array}$} \\
\hline It relieves stress for me & 2018 & 45.4 & 212 & 55.5 & 330 & 50.2 & 1158 & 45.9 & 318 & 36.1 \\
\hline It helps me to feel good about myself & 2784 & 62.7 & 270 & 70.7 & 406 & 61.8 & 1657 & 65.7 & 451 & 51.3 \\
\hline I want to be in control of my weight & 2266 & 51.0 & 231 & 60.5 & 339 & 51.6 & 1304 & 51.7 & 392 & 44.5 \\
\hline $\begin{array}{l}\text { I want to do everything possible to } \\
\text { maintain/improve my health }\end{array}$ & 2037 & 45.9 & 190 & 49.7 & 327 & 49.8 & 1206 & 47.8 & 314 & 35.7 \\
\hline I want to live a long life & 1885 & 42.4 & 174 & 45.5 & 291 & 44.3 & 1105 & 43.8 & 315 & 35.8 \\
\hline I want to be strong & 2073 & 46.7 & 186 & 48.7 & 297 & 45.2 & 1258 & 49.9 & 332 & 37.7 \\
\hline $\begin{array}{l}\text { It is a good way for me to practice } \\
\text { discipline }\end{array}$ & 1239 & 27.9 & 103 & 27.0 & 179 & 27.2 & 772 & 30.6 & 185 & 21.0 \\
\hline $\begin{array}{l}\text { Not applicable as I don't exercise } \\
\text { regularly }\end{array}$ & 778 & 17.5 & 52 & 13.6 & 110 & 16.7 & 394 & 15.6 & 222 & 25.2 \\
\hline $\begin{array}{l}\text { Not applicable as I typically don't } \\
\text { maintain a nutritious diet }\end{array}$ & 489 & 11.0 & 25 & 6.5 & 62 & 9.4 & 242 & 9.6 & 160 & 18.2 \\
\hline \multicolumn{11}{|l|}{$\begin{array}{l}\text { Are you interested in participating in } \\
\text { wellness programming when you } \\
\text { return to campus? }\end{array}$} \\
\hline None & 1804 & 40.6 & 155 & 40.6 & 236 & 35.9 & 1025 & 40.6 & 388 & 44.1 \\
\hline A little & 1171 & 26.4 & 100 & 26.2 & 167 & 25.4 & 681 & 27.0 & 223 & 25.3 \\
\hline Somewhat & 775 & 17.5 & 72 & 18.8 & 147 & 22.4 & 409 & 16.2 & 147 & 16.7 \\
\hline Moderately so & 444 & 10.0 & 37 & 9.7 & 68 & 10.4 & 261 & 10.3 & 78 & 8.9 \\
\hline Very much so & 241 & 5.4 & 18 & 4.7 & 38 & 5.8 & 143 & 5.7 & 42 & 4.8 \\
\hline Missing & 6 & 0.1 & 0 & 0.0 & 1 & 0.2 & 3 & 0.1 & 2 & 0.2 \\
\hline
\end{tabular}




\section{Virtual Programming and Services: Accessibility, Interest, and Utilization}

Overall, most students reported being able to access virtual wellness programming, however, 5.8\% reported that they could not access the virtual programming. Forty-seven percent of students were satisfied (either agreed or strongly agreed) with the amount of virtual programming provided, and $39.8 \%$ were neutral about their satisfaction with the amount of virtual programming. Thirty-six percent of students had used virtual programing prior to COVID-19 (either agreed or strongly agreed). More than $50 \%$ of students either "agreed" or "strongly agreed" that they will use virtual programming offered by the University in the future (Table 7).

Table 7. Accessibility, Interest, and Utilization of Virtual Programming and Services

\begin{tabular}{|c|c|c|c|c|c|c|c|c|c|c|}
\hline & \multicolumn{2}{|c|}{$\begin{array}{c}\text { All } \\
(n=4441)\end{array}$} & \multicolumn{2}{|c|}{$\begin{array}{l}\text { Professional } \\
\text { Students } \\
(\mathbf{n}=\mathbf{3 8 2})\end{array}$} & \multicolumn{2}{|c|}{$\begin{array}{l}\text { Graduate } \\
\text { Students } \\
(n=657)\end{array}$} & \multicolumn{2}{|c|}{$\begin{array}{l}\text { Central Campus } \\
\text { Undergraduate } \\
\text { Students } \\
(\mathbf{n}=\mathbf{2 5 2 2})\end{array}$} & \multicolumn{2}{|c|}{$\begin{array}{c}\text { Regional } \\
\text { Campus } \\
\text { Undergraduate } \\
\text { Students } \\
(\mathbf{n}=\mathbf{8 8 0})\end{array}$} \\
\hline & $\mathbf{N}$ & $\%$ & $\mathbf{N}$ & $\%$ & $\mathbf{N}$ & $\mathbf{N}$ & $\%$ & $\mathbf{N}$ & $\%$ & $\mathbf{N}$ \\
\hline \multicolumn{11}{|c|}{$\begin{array}{l}\text { I am able to access virtual } \\
\text { programming and services offered by } \\
\text { the University. }\end{array}$} \\
\hline Missing & 24 & 0.5 & 4 & 1.0 & 4 & 0.6 & 13 & 0.5 & 3 & 0.3 \\
\hline Strongly disagree & 115 & 2.6 & 15 & 3.9 & 18 & 2.7 & 51 & 2.0 & 31 & 3.5 \\
\hline Disagree & 143 & 3.2 & 10 & 2.6 & 23 & 3.5 & 84 & 3.3 & 26 & 3.0 \\
\hline Neither disagree or agree & 668 & 15.0 & 70 & 18.3 & 113 & 17.2 & 353 & 14.0 & 132 & 15.0 \\
\hline Agree & 1836 & 41.3 & 151 & 39.5 & 233 & 35.5 & 1085 & 43.0 & 367 & 41.7 \\
\hline Strongly agree & 1655 & 37.3 & 132 & 34.6 & 266 & 40.5 & 936 & 37.1 & 321 & 36.5 \\
\hline \multicolumn{11}{|c|}{$\begin{array}{l}\text { I am satisfied with the amount of } \\
\text { virtual programming and services } \\
\text { offered by the University. }\end{array}$} \\
\hline Missing & 42 & 0.9 & 6 & 1.6 & 6 & 0.9 & 23 & 0.9 & 7 & 0.8 \\
\hline Strongly disagree & 150 & 3.4 & 12 & 3.1 & 22 & 3.3 & 86 & 3.4 & 30 & 3.4 \\
\hline Disagree & 396 & 8.9 & 39 & 10.2 & 53 & 8.1 & 234 & 9.3 & 70 & 8.0 \\
\hline Neither disagree or agree & 1769 & 39.8 & 162 & 42.4 & 271 & 41.2 & 1049 & 41.6 & 287 & 32.6 \\
\hline Agree & 1477 & 33.3 & 131 & 34.3 & 203 & 30.9 & 820 & 32.5 & 323 & 36.7 \\
\hline Strongly agree & 607 & 13.7 & 32 & 8.4 & 102 & 15.5 & 310 & 12.3 & 163 & 18.5 \\
\hline \multicolumn{11}{|c|}{$\begin{array}{l}\text { I had used virtual programming or } \\
\text { services prior to COVID-19. }\end{array}$} \\
\hline Missing & 44 & 1.0 & 6 & 1.6 & 6 & 0.9 & 25 & 1.0 & 7 & 0.8 \\
\hline Strongly disagree & 852 & 19.2 & 75 & 19.6 & 138 & 21.0 & 496 & 19.7 & 143 & 16.3 \\
\hline Disagree & 1298 & 29.2 & 117 & 30.6 & 200 & 30.4 & 755 & 29.9 & 226 & 25.7 \\
\hline Neither disagree or agree & 664 & 15.0 & 62 & 16.2 & 107 & 16.3 & 350 & 13.9 & 145 & 16.5 \\
\hline Agree & 1075 & 24.2 & 91 & 23.8 & 139 & 21.2 & 617 & 24.5 & 228 & 25.9 \\
\hline Strongly agree & 508 & 11.4 & 31 & 8.1 & 67 & 10.2 & 279 & 11.1 & 131 & 14.9 \\
\hline \multicolumn{11}{|c|}{$\begin{array}{l}\text { I will use virtual programming or } \\
\text { services offered by the University in } \\
\text { the future. }\end{array}$} \\
\hline Missing & 43 & 1.0 & 6 & 1.6 & 6 & 0.9 & 27 & 1.1 & 4 & 0.5 \\
\hline Strongly disagree & 179 & 4.0 & 18 & 4.7 & 20 & 3.0 & 103 & 4.1 & 38 & 4.3 \\
\hline Disagree & 313 & 7.0 & 31 & 8.1 & 38 & 5.8 & 187 & 7.4 & 57 & 6.5 \\
\hline Neither disagree or agree & 1366 & 30.8 & 108 & 28.3 & 192 & 29.2 & 781 & 31.0 & 285 & 32.4 \\
\hline Agree & 1779 & 40.1 & 161 & 42.1 & 266 & 40.5 & 1037 & 41.1 & 315 & 35.8 \\
\hline Strongly agree & 761 & 17.1 & 58 & 15.2 & 135 & 20.5 & 387 & 15.3 & 181 & 20.6 \\
\hline
\end{tabular}




\section{DISCUSSION}

This study's results indicate a critical need to continue to accelerate access to mental health services along with preventive and early evidence-based interventions and mental health and wellness programming. An alarming rate of students met clinical cut-offs for anxiety (39\%) and depression (24\%), while an equally alarming rate of students indicated that they were experiencing burnout (40\%). A pre-COVID cross-sectional study of professional and graduate students which used the same screening tools (PHQ-2 and GAD-2) reported that 17\% of students met the clinical cut off for depression and 14\% met the clinical cut off for anxiety (Hoying, Melnyk, Hutson, \& Tan, 2020). While study populations were not identical (i.e., Hoying et al. [2020] did not include undergraduate students or measure burnout), a rough comparison indicates that there has been a $1.4 \mathrm{x}$ increase in depression and $3 \mathrm{x}$ increase in anxiety. The depression increase is identical to a recent COVID-19 student mental health analysis, and the increase in anxiety is slightly higher (3x vs 2x; Chirikov et al., 2020).

At least $30 \%$ of students were not at all confident about being able to return to campus safely and, when broken down by race/ethnicity, minority student populations had higher levels of no confidence than non-Hispanic White student populations. The same trend was observed for depression and anxiety, with minority students reporting significantly more symptoms than non-Hispanic white students. Minority populations have been impacted by the COVID-19 pandemic significantly more than their white counterparts, with structural factors as key contributors (Van Dorn, Cooney, \& Sabin, 2020). In the U.S., minority populations face inequalities in terms of discrimination, access to healthcare, and disproportionally working in essential worker roles which substantially impacts the ability to social distance. Therefore, IHEs must prioritize and consider how they can decrease implicit bias and discrimination in addition to increasing access to healthcare on their campuses for these disproportionally impacted populations.

A WHO (2020) mental health rapid assessment reported that $60 \%$ of countries have experienced major disruptions to mental health services for vulnerable people and that the greatest impact has been on preventative services. Thus, IHEs can serve as a means for empowering students and limiting disruptions to preventative mental health care. In an effort to continue to shift the paradigm from crisis intervention to prevention and early intervention, the University has further expanded its evidence-based mental health and wellness programing with funding from the CARES Act (Coronavirus Aid, Relief, and Economic Security Act, 2019-2020). The MINDSTRONG cognitive-behavioral skills building program (also known as Creating Opportunities for Personal Empowerment [COPE] in the literature) is effective in decreasing depression, anxiety, stress, and suicidal ideation and increasing healthy lifestyle behaviors by improving mental resiliency and coping (Hart Abney, Lusk, Hovermale, \& Melnyk, 2019; Melnyk et al., 2015; Melnyk, Hoying, \& Tan, 2020). MINDSTRONG is now required in certain colleges and is offered as a one credit course program. Equipping college students with evidence-based skills, such as mindfulness and cognitive-behavioral/coping skills, can build resiliency and protective factors to help prevent mental health disorders (Galante et al., 2018; Regehr, Glancy, \& Pitts, 2013). Universities should consider integrating preventive evidence-based programming into required course work. If not required, innovative strategies to engage students in this type of programming is necessary. Additionally, the University's College of Nursing created a telehealth wellness hub in which faculty and advanced practice nurse practitioner students conduct total health and well-being assessments along with health coaching to students across campus.

This study's findings demonstrated that unhealthy lifestyle behaviors were on the rise in a substantial proportion of students who were using them to cope with the current pandemic. Increases in unhealthy lifestyle behaviors in 
younger populations also have been reported in several other studies (Chirikov et al., 2020; Gallè et al., 2020; Park et al., 2020; Zheng et al., 2020). As the risk of developing a chronic condition can be lessened by engaging in healthy lifestyle behaviors (CDC, 2020), universities must create cultures of wellness in which healthy behaviors are the default choice or norm for students, faculty, and staff. If the trends in unhealthy behaviors are not reversed, the prevalence of chronic diseases will continue to impact future generations.

Improving student mental health, well-being, and healthy lifestyle behaviors requires that comprehensive wellness cultures be built and sustained at universities throughout the country. Leadership and manager engagement are vital for creating and sustaining strong wellness cultures, as are grassroots initiatives like wellness champions (Amaya et al., 2020; Melnyk, Amaya, Szalacha, \& Hoying, 2016). In a 2019 case study published by the National Academy of Medicine's Action Collaborative on Clinician Well-being and Resilience (Cappelucci, Zindel, Knight, Busis, \& Alexander, 2019), medical students reflected this belief with statements like "Our Deans and leadership are so important for student well-being. Their transparency, honesty, and support trickles down to students, and we feel that we have a strong support system when times are hard." Presidents, deans, and faculty will continue to play a critical role in encouraging, engaging, and supporting their students to participate in wellness programming and activities. A new tool entitled "Check and Improve Your Stress and Well-being" has been launched and piloted with the University's students. This tool provides students with the opportunity to check and monitor their own levels of stress, anxiety, depression, and healthy lifestyle behaviors along with providing them with a variety of evidencebased resources and support.

Slightly less than $50 \%$ of students believed that they knew how to best prevent the spread of COVID-19 and only $40 \%$ of students at least somewhat believed that their peers would follow appropriate safety protocols when returning to campus. A sense of safety or lack thereof impacts school culture (Aldrige \& McChesney, 2018), thus, continued educational programming and communications on the topic of preventing COVID-19 will be important, as increased COVID-19 knowledge is significantly associated with less negative beliefs about COVID-19 preventative practices (Zhong et al., 2020). To engage students in solutions to these issues, a student innovation challenge was launched at the University to encourage students to become more involved in generating innovative ideas to improve compliance with mask wearing and physical distancing in on-campus and off-campus residences as well as improving the mental health and well-being of students.

A strength of this study is that it used a random sample so that findings could be generalized to the rest of the University's population. Furthermore, the demographic findings were similar to those posted by the University. A limitation was the cross sectional design and 30\% response rate, which is lower than the recommended $40 \%$ (Story $\&$ Tai, 2019). In addition, the participants in this study were all from one IHE, therefore, generalizability to other IHE students across the U.S. is limited. However, the rates of anxiety and depression are similar to the Student Experience in the Research University (SERU) Consortium survey (Chirikov et al., 2020) and the Morbidity and Mortality Weekly Report (Czeisler et al., 2020).

\section{CONCLUSION}

The high percentages of clinical anxiety and depression in the student population are alarming, therefore continuing to understand the impact that COVID-19 has had on the mental health of the student population and which evidence-based interventions are most effective remains a top priority, especially for ethnic and racial 
diversity populations. The University's Chief Wellness Officer, One University Health and Wellness Council, and Office of Student Life leadership will continue to monitor outcomes and plan targeted evidence-based strategies to enhance student health and well-being. Even after the COVID-19 pandemic has passed, diverting resources to build and sustain cultures of wellness within IHE will continue to be important to improving population health and wellbeing for the next generation. 


\section{REFERENCES}

Aldridge, J. M., \& McChesney, K. (2018). The relationships between school climate and adolescent mental health and wellbeing: A systematic literature review. International Journal of Educational Research, 88, 121-145. https://doi.org/10.1016/j.ijer.2018.01.012

Amaya, M., Batista, L., Melnyk, B. M., Winn, J., Johnson, N., \& Buffington, B. (2020). Wellness champions: A critical strategy for universities to enhance population health and wellbeing during the COVID-19 pandemic. Building Healthy Academic Communities Journal, 4(2), 7-16. https:/ /doi.org/10.18061/bhac.v4i2.7836

Auerbach, R. P., Alonso, J., Axinn, W. G., Cuijpers, P., Ebert, D. D., Green, J. G., .. Nock, M. K. (2016). Mental disorders among college students in the World Health Organization world mental health surveys. Psychological Medicine, 46(14), 2955-2970. https://doi.org/10.1017/s0033291716001665

Cappelucci, K., Zindel, M., Knight, H. C., Busis, N., \& Alexander, C. (2019). Clinician well-being at Ohio State University: A case study. NAM Perspectives. https://doi.org/10.31478/201908b

Centers for Disease Control and Prevention. (2020, September 15). How you can prevent chronic disease. Retrieved from http://www.cdc.gov/chronicdisease/about/prevent/index.html

Chirikov, I., Soria, K. M., Horgos, B, \& Jones-White, D. (2020). Undergraduate and graduate students' mental health during the COVID-19 pandemic. UC Berkeley: Center for Studies in Higher Education. Retrieved from https://escholarship.org/uc/item/80k5d5hw

Coronavirus Aid, Relief, and Economic Security Act, S. 3548, 116th Cong (2019-2020). Retrieved from https:/ / www.congress.gov/bill/116th-congress/senate-bill/3548/text?q=product + actualizaci $\% C 3 \%$ B3n

Czeisler, M. É., Lane, R. I., Petrosky, E., Wiley, J. F., Christensen, A., Njai, R., .. Czeisler, C.A., 2020. Mental health, substance use, and suicidal ideation during the COVID-19 pandemic-United States, June 24-30, 2020. Morbidity and Mortality Weekly Report, 69(32), 1049. https://doi.org/10.15585/mmwr.mm6932a1

Dolan, E. D., Mohr, D., Lempa, M., Joos, S., Fihn, S. D., Nelson, K. M., \& Helfrich, C. D. (2015). Using a single item to measure burnout in primary care staff: a psychometric evaluation. Journal of General Internal Medicine, 30(5), 582-587. https://doi.org/10.1007/s11606-014-3112-6

Galante, J., Dufour, G., Vainre, M., Wagner, A. P., Stochl, J., Benton, A., .. Jones, P. B. (2018). A mindfulnessbased intervention to increase resilience to stress in university students (the Mindful Student Study): A pragmatic randomised controlled trial. The Lancet Public Health, 3(2), e72-e81. https://doi.org/10.1016/S2468-2667(17)30231-1

Gallè, F., Sabella, E. A., Ferracuti, S., De Giglio, O., Caggiano, G., Protano, C., ... Montagna, M. T. (2020). Sedentary behaviors and physical activity of Italian undergraduate students during lockdown at the time of CoViD - 19 pandemic. International Journal of Environmental Research and Public Health, 17(17), 6171. https://doi.org/10.3390/ijerph17176171

Hart Abney, B. G., Lusk, P., Hovermale, R., \& Melnyk, B. M. (2019). Decreasing depression and anxiety in college youth using the Creating Opportunities for Personal Empowerment Program (COPE). Journal of the American Psychiatric Nurses Association, 25(2), 89-98. https://doi.org/10.1177/1078390318779205

Hoying, J., Melnyk, B. M., Hutson, E., \& Tan, A. (2020). Prevalence and Correlates of Depression, Anxiety, Stress, Healthy Beliefs, and Lifestyle Behaviors in First-Year Graduate Health Sciences Students. Worldviews on Evidence-Based Nursing, 17(1), 49-59. https://doi.org/10.1111/wvn.12415 
Karyotaki, E., Cuijpers, P., Albor, Y., Alonso, J., Auerbach, R. P., Bantjes, J., ... Kessler, R. C. (2020). Sources of stress and their associations with mental disorders among college students: Results of the World Health Organization World Mental Health Surveys International College Student Initiative. Frontiers in Psychology, 11, 1759. https://doi.org/10.3389/fpsyg.2020.01759

Kroenke, K., Spitzer, R. L., \& Williams, J. B. (2003) The Patient Health Questionnaire-2: Validity of a two-item depression screener. Medical Care, 41(11):1284-92. https://doi.org/10.1097/01.mlr.0000093487.78664.3c

Kroenke, K., Spitzer, R. L., Williams, J. B., Monahan, P. O., \& Löwe, B. (2007). Anxiety disorders in primary care: Prevalence, impairment, comorbidity, and detection. Annals of Internal Medicine, 146(5), 17-325. https://doi.org/10.7326/0003-4819-146-5-200703060-00004

Kvam, S., Kleppe, C. L., Nordhus, I. H., \& Hovland, A. (2016). Exercise as a treatment for depression: A metaanalysis. Journal of Affective Disorders, 202, 67-86. https://doi.org/10.1016/j.jad.2016.03.063

McLeroy, K. R., Steckler, A., \& Bibeau, D. (1988). The social ecology of health promotion interventions. Health Education Quarterly, 15(4), 351-377. https://doi.org/10.1177/109019818801500401

Melnyk, B. M., Amaya, M., Szalacha, L. A., \& Hoying, J. (2016). Relationships among perceived wellness culture, healthy lifestyle beliefs, and healthy behaviors in university faculty and staff: Implications for practice and future research. Western Journal of Nursing Research, 38(3), 308-324. https:/ / doi.org/10.1177/0193945915615238

Melnyk, B. M., Amaya, M., Szalacha, L. A., Hoying, J., Taylor, T., \& Bowersox, K. (2015). Feasibility, acceptability, and preliminary effects of the COPE Online Cognitive-Behavioral Skill-Building Program on mental health outcomes and academic performance in freshmen college students: A randomized controlled pilot study. Journal of Child and Adolescent Psychiatric Nursing, 28(3), 147-154. https://doi.org/10.1111/jcap.12119

Melnyk, B.M, Hoying, J., \& Tan, A. (2020). Effects of the MINDSTRONGC CBT-based program on depression, anxiety and healthy lifestyle behaviors in graduate health sciences students. Journal of American College Health, 1-9. https://doi.org/10.1080/07448481.2020.1782922

Melnyk, B.M., \& Neale, S. 9 dimensions of wellness. (2018). American Nurse Today, 13(1). https://www.myamericannurse.com/wp-content/uploads/2018/01/ant1-Wellness-1218.pdf

Melnyk, B. M., Tan, A., Hsieh, A. P., Gawlik, K., Arslanian-Engoren, C., Braun, L.T., ... Orsolini, L. (2021). Critical care nurses' physical and mental health, worksite wellness support, and medical errors. American Journal of Critical Care, 30(3), 176-184. https://doi.org/10.4037/ajcc2021301

National Academies of Sciences, Engineering, and Medicine. (2021). Mental health, substance use, and wellbeing in higher education: Supporting the whole student. Washington, DC: The National Academies Press. https://doi.org/10.17226/26015.

Park, C. L., Russell, B. S., Fendrich, M., Finkelstein-Fox, L., Hutchison, M., \& Becker, J. (2020). Americans' COVID-19 stress, coping, and adherence to CDC guidelines. Journal of General Internal Medicine, 35(8), 22962303. https://doi.org/10.1007/s11606-020-05898-9

Regehr, C., Glancy, D., \& Pitts, A. (2013) Interventions to reduce stress in university students: A review and metaanalysis. Journal of Affective Disorders, 148(1), 1-11. https://doi.org/10.1016/j.jad.2012.11.026

Staples, L. G., Dear, B. F., Gandy, M., Fogliati, V., Fogliati, R., Karin, E., ... Titov, N. (2019). Psychometric properties and clinical utility of brief measures of depression, anxiety, and general distress: The PHQ-2, GAD-2, and K-6. General Hospital Psychiatry, 56, 13-18. https://doi.org/10.1016/j.genhosppsych.2018.11.003 
Stonerock, G. L., Hoffman, B. M., Smith, P. J., \& Blumenthal, J. A. (2015). Exercise as treatment for anxiety: Systematic review and analysis. Annals of Behavioral Medicine, 49(4), 542-556.

https://doi.org/10.1007/s12160-014-9685-9

Story, D. A., \& Tait, A. R. (2019). Survey research. Anesthesiology, 130(2), 192-202. https://doi.org/10.1097/ALN.0000000000002436

Van Dorn, A., Cooney, R. E., \& Sabin, M. L. (2020). COVID-19 exacerbating inequalities in the US. Lancet, 395(10232), 1243-1244. https://doi.org/10.1016/s0140-6736(20)30893-x

World Health Organization. (2020) The impact of COVID-19 on mental, neurological, and substance use services: Results of a rapid assessment. Retrieved from https://www.who.int/news-room/detail/05-10-2020-covid19-disrupting-mental-health-services-in-most-countries-who-survey. 2020 Oct 5.

Zhai, Y., \& Du, X. (2020). Addressing collegiate mental health amid COVID-19 pandemic. Psychiatry Research, 288, 113003. https://doi.org/10.1016/j.psychres.2020.113003

Zheng, C., Huang, W.Y., Sheridan, S., Sit, C.H., Chen, X.K., Wong, S.H. (2020) COVID-19 pandemic brings a sedentary lifestyle in young adults: A cross-sectional and longitudinal study. Int J Environ Res Public Health. 2020 Aug 19;17(17):E6035. https://doi.org/10.3390/ijerph17176035

Zhong, B. L., Luo, W., Li, H. M., Zhang, Q. Q., Liu, X. G., Li, W. T., \& Li, Y. (2020). Knowledge, attitudes, and practices towards COVID-19 among Chinese residents during the rapid rise period of the COVID-19 outbreak: A quick online cross-sectional survey. International Journal of Biological Sciences, 16(10), 1745. https://doi.org/10.7150/ijbs.45221

Address Author correspondence to:

Bernadette Mazurek Melnyk, PhD, APRN-CNP, FAANP, FNAP, FAAN

The Ohio State University

145 Newton Hall

1585 Neil Avenue Columbus, OH 43210

Melnyk.15@osu.edu 